\title{
Kuttner, Robert (2018), Can Democracy Survive Global Capitalism?
}

João Rodrigues

\section{OpenEdition}

\section{Journals}

Edição electrónica

URL: http://journals.openedition.org/rccs/9360

DOI: $10.4000 /$ rccs.9360

ISSN: 2182-7435

Editora

Centro de Estudos Sociais da Universidade de Coimbra

\section{Edição impressa}

Data de publição: 1 setembro 2019

Paginação: 201-204

ISSN: 0254-1106

\section{Refêrencia eletrónica}

João Rodrigues, « Kuttner, Robert (2018), Can Democracy Survive Global Capitalism? », Revista Crítica de Ciências Sociais [Online], 119 | 2019, posto online no dia 06 agosto 2019, consultado o 24 setembro 2020. URL : http://journals.openedition.org/rccs/9360; DOI : https://doi.org/10.4000/rccs.9360 


\section{Recensões}

\section{Tooze, Adam (2018), Crashed: How a Decade of Financial Crises Changed the World. New York: Allen Lane, Penguin Books, 706 pp.}

Há momentos de descontinuidade profunda na história das sociedades, que marcam o mundo de forma decisiva e estão condenados a ocupar um lugar de destaque na memória coletiva. A grande recessão de 2007-2008 foi certamente um desses momentos. Depois da violenta crise financeira, nada seria como dantes. É esse o tema central do recente livro de Adam Tooze, Crashed: How a Decade of Financial Crises Changed the World.

"A história que o livro conta", como explica o autor, "é a de um descarrilamento" (p. 15). ${ }^{1}$ O livro organiza-se em quatro partes: "A formação da tempestade", sobre o desenvolvimento dos desequilíbrios estruturais que originaram a crise; "A crise global”, que discute o colapso e as respostas imediatas; "Zona euro", com foco no continente europeu; e "Réplicas", sobre a década que se seguiu. Embora já muito tenha sido escrito sobre o assunto, este é um dos relatos mais informados, completos e abrangentes sobre a Grande Recessão e as suas consequências. A obra combina o foco nas dinâmicas do sistema financeiro com uma discussão dos conflitos dentro dos países e entre países. A análise do autor integra as esferas financeira, (geo)política e socioeconómica da história da última década (sendo a última, talvez, a menos tratada ao longo do livro). Poucos autores o terão conseguido fazer com a eloquência de Adam Tooze, historiador económico e professor na Universidade de Columbia, nos Estados Unidos da América (EUA). Tooze começa por recordar como a maioria dos economistas previram a "crise errada", por estarem apenas focados nos desequilíbrios comerciais entre os EUA e a China e ignorarem os riscos intrínsecos do próprio sistema financeiro. $\mathrm{O}$ autor parte depois para uma análise detalhada dos mecanismos financeiros complexos por detrás da crise e das diferentes respostas (programas de estímulos à economia ou de austeridade). A cronologia que o autor apresenta não se resume aos principais desenvolvimentos da crise nos EUA e nos países da Europa Ocidental, mas também na Rússia, na Europa de Leste, na China e noutros países asiáticos, ocupando uma parte substancial do livro com uma discussão das diferentes respostas das autoridades e dos conflitos geopolíticos. Nas décadas que antecederam a crise, na zona euro, as diferenças nos modelos de crescimento e nas estruturas produtivas dos diferentes países originaram desequilíbrios entre países excedentários e deficitários. ${ }^{2} \mathrm{O}$ afluxo de capitais para os segundos alimentou bolhas especulativas (no imobiliário ou nos mercados bolsistas) e tendências de endividamento cumulativo. O extraordinário desenvolvimento de Wall Street e dos lucros do sistema financeiro norte-americano podem também ser compreendidos pela necessidade

\footnotetext{
1 Todas as traduções são do autor.

2 Storm, Servaas; Naastepad, C. W. M. (2016), "Myths, Mix-Ups, and Mishandlings: Understanding the Eurozone Crisis", International Journal of Political Economy, 45(1), 46-71.
} 
de captar capitais para financiar os défices dos EUA, oferecendo ativos de maior risco com retornos compensadores para os investidores. Os bancos europeus foram os principais envolvidos nestas operações financeiras de risco, tornando-se bastante dependentes do mercado financeiro norte-americano num contexto de financeirização do capitalismo ocidental. ${ }^{3}$

Embora a quebra dos preços das casas e dos créditos subprime tenha sido a causa imediata da crise, Tooze recorda que esta tem origem na intensificação dos laços financeiros transatlânticos entre os EUA e a Europa nas décadas anteriores à crise, facilitada pela vaga de desregulação do setor que permitiu aumentar significativamente o fluxo de capitais e a alavancagem dos bancos. Os acontecimentos de 2007-2008 nos EUA, a quebra da confiança no sistema e o consequente congelamento do crédito, do qual todos os bancos e instituições estavam dependentes, fariam ruir o castelo de cartas do sistema financeiro, provocando a recessão mais profunda desde a Grande Depressão de 1929. "Nunca antes, nem sequer na década de 1930, tínhamos assistido à iminência da implosão de um sistema tão amplo e interdependente" (p. 9), escreve Tooze. A queda do Lehman Brothers, em setembro de 2008, seria apenas o início.

A crise da dívida privada foi transformada numa crise da dívida pública através da absorção das perdas financeiras pelos Estados. No livro Austeridade: a história de uma ideia perigosa, Mark Blyth descreveu esta operação como o maior embuste ("bait and switch") da história contemporânea. ${ }^{4}$ No caso da zona euro, a austeridade foi o mecanismo de socialização destas perdas, passando o encargo para as populações. A agudização da crise e a generalização do desemprego foram, por isso, resultado de escolhas políticas das instituições europeias. Nas palavras do autor, este foi "um espetáculo que deve inspirar indignação. Milhões de pessoas sofreram sem nenhuma razão para isso" (p. 15).

Em linha com a tradição da economia política institucionalista, Tooze reconhece como utópica a ideia de que existem mercados como entidades politicamente neutras e cujo funcionamento não depende de regulações, normas e hábitos sociais. Ao expor os desequilíbrios do processo de financeirização e a necessidade de recurso ao financiamento do Estado para evitar situações de insolvência dos bancos, a crise acabou também com o mito da desregulação virtuosa - esta "derrota histórica" foi a única forma de salvar um sistema em falência.

A política monetária expansionista da Reserva Federal norte-americana teve, por isso, um papel crucial para evitar o aprofundamento da crise global, permitindo resgatar as instituições financeiras norte-americanas e oferecer liquidez aos bancos europeus (que precisavam urgentemente de reservas de dólares) através de medidas opacas como as currency swap lines. Se dúvidas houvesse sobre a hegemonia do dólar no sistema financeiro internacional, estas ficaram desfeitas com a atuação da Reserva Federal como "emprestador de último recurso" da economia global. Tooze destaca a importância deste facto que, em conjunto com o poderio militar, continuam a garantir o papel dos EUA como principal potência mundial (ainda que ameaçada pela ascensão da China). Na zona euro,

\footnotetext{
${ }^{3}$ Lapavitsas, Costas (2013), Profiting without Producing; How Finance Exploits Us All. London: Verso.

${ }^{4}$ Blyth, Mark (2013), Austeridade: a história de uma ideia perigosa. Lisboa: Quetzal Editores. Tradução de Freitas e Silva.
} 
a rigidez de Angela Merkel e do governo alemão levou a que bloqueassem qualquer tipo de atuação contracíclica do Banco Central Europeu até que fosse demasiado tarde e a crise já tivesse devastado os países da periferia, com consequências sociais e políticas profundas (na Grécia, o país mais afetado, a taxa de desemprego jovem continua hoje próxima de $40 \%$ ).

Por outro lado, a resposta expansionista da China à crise global merece a análise de Tooze. Ameaçada pela desaceleração do comércio, que afetou as suas exportações, a China desenvolveu um plano de resposta através de um reforço significativo do investimento público (de cerca de 12,5\% do PIB) aliado a uma política monetária expansionista que permitiu atingir altas taxas de crescimento e emprego, ajudando a contrariar a tendência de recessão global. Quais as consequências da Grande Recessão no rumo recente do capitalismo ocidental? A pergunta ocupa a discussão da última secção do livro, embora a resposta seja complexa e o autor procure evitar leituras deterministas. Mais de dez anos depois da crise, a política monetária expansionista pode ter evitado danos ainda maiores, mas não resolveu os problemas mais profundos, limitando-se a contribuir para recuperar os ganhos do sistema financeiro, sem que tenha havido alterações substanciais no campo da regulação. Além disso, a austeridade (aplicada sobretudo na zona euro) é responsável pela lenta recuperação destas economias e pela acentuação das desigualdades sociais. É difícil não associar os efeitos devastadores da crise e das escolhas políticas de preservação do sistema à erosão dos partidos tradicionais e à ascensão de candidatos alternativos, mobilizando a revolta social. A eleição de Donald Trump nos EUA e a ascensão dos partidos de extrema-direita por toda a Europa são exemplos desta "grande crise da modernidade" (p. 616). As elites ocidentais tradicionais estão a pagar o preço de sujeitarem a democracia à disciplina dos mercados financeiros.

Vicente Ferreira

\section{Kuttner, Robert (2018), Can Democracy Survive Global Capitalism? New York/London: Norton, 360 pp.}

Da recessão democrática à democracia iliberal, muitos são os que agora diagnosticam uma crise das democracias ditas liberais de matriz ocidental. Estas estariam a ser postas em causa por uma antielitista raiva popular, fomentada por nacional-populistas. Nos Estados Unidos da América (EUA), tal tendência teria um nome óbvio: Donald Trump.

Em contraste com uma literatura superficial, o último livro de Robert Kuttner tem como título aquela que é talvez a questão mais importante da economia política internacional nas presentes circunstâncias históricas: "será que a democracia pode sobreviver ao capitalismo global?".

Trata-se de um livro escrito por um economista, que é um intelectual público, de orientação vincadamente social-democrata; um "liberal", na peculiar terminologia dos EUA, da ala esquerda dos democratas, um dos fundadores da revista American Prospect e do Economic Policy Institute, o principal think-tank ligado ao crescentemente frágil movimento sindical norte-americano. Enquanto jornalista, colunista e ensaísta, várias vezes premiado, tem escrutinado as perversas tendências no campo da economia política desde o seu 
primeiro livro, de 1980, sobre a revolta fiscal dos ricos, na altura só a começar. Os seus livros costumam de resto conter boas sínteses, combinando investigação aturada e divulgação da mais relevante literatura académica num estilo acessível, beneficiando também de ligações universitárias. Trata-se da versão crítica de um perfil habitual na enviesada esfera pública dos EUA, hegemonizada por intelectuais públicos neoliberais. Estes últimos têm há muito tempo a seu favor o maciço financiamento privado para cruzadas intelectuais e mediáticas.

O livro de Robert Kuttner inscreve-se numa linha que não separa - antes articula - as formas institucionais, ditas políticas, de que a democracia se tem de revestir e as formas institucionais que moldam as relações sociais no campo da provisão (a economia substantiva, como diria Karl Polanyi, uma das principais referências mobilizadas).

A história da democracia e das suas crises não pode ser separada da história do capitalismo e das suas crises, bem como da história das alternativas sistémicas pós-capitalistas. A história da democracia é também e sobretudo a história da luta de classes e das suas cristalizações institucionais nacionais; uma história de economia política, em suma, contra uma abordagem puramente política ou economicista. Longe de ser uma parceria natural, a relação entre capitalismo e democracia é intrinsecamente tensa. Historicamente, a democracia baseada no sufrágio universal só pôde florescer no quadro do que Kuttner apoda de economias mistas, uma realidade institucional do mundo desenvolvido a seguir à Segunda Guerra Mundial. Por sua vez, este tipo de economia, e a maior e mais partilhada prosperidade que gerou, só pôde florescer no quadro de Estados nacionais com vontade e capacidade políticas para conter o antidemocrático poder estrutural do capital, criando-lhe freios e contrapesos. Neste contexto, Kuttner explora com particular sagacidade a relação entre a imposição de mecanismos nacionais para regular a finança e o comércio internacionais (incluindo controlos à entrada e à saída de capitais e um certo protecionismo) e os ganhos institucionais, económicos e políticos das classes trabalhadoras (da desmercadorização parcial das relações laborais, aos ganhos salariais, passando pela política económica orientada para o pleno emprego). A relação anterior está no centro da economia política keynesiana, embora nem sempre seja tão visibilizada como o é neste livro. O conhecimento da história permite-lhe, além do mais, comparações e analogias pertinentes, tão necessárias em economia política: por exemplo, a comparação entre o governo trabalhista britânico a partir de 1945 , com uma economia mais endividada devido à guerra, e o governo socialista da presidência de François Mitterrand, em França, do início da década de 1980; o primeiro - porque tinha a finança sob controlo, a repressão financeira, como lhe chamam os neoliberais - conseguiu uma margem de manobra bem superior ao segundo, compelido a render-se ao poder da finança dita privada e à integração europeia que a estava decisivamente reforçando.

Sendo algo melancólico, o olhar de Robert Kuttner sobre o período que vai da Segunda Guerra Mundial aos turbulentos anos 1970 enfatiza as circunstâncias históricas únicas e fortuitas que geraram um capitalismo relativamente democrático - dos efeitos político-ideológicos da Grande Depressão, em especial o New Deal de Franklin D. Roosevelt, "o mais eficaz presidente populista e progressista da história dos EUA" (p. 286), à existência de um campo socialista liderado pela União 
Soviética. Depois de décadas de recuo democrático, de erosão e desaparecimento dos freios internos e externos ao poder do capital, o tipo de circunstâncias que geraram o capitalismo democrático é hoje reconhecidamente mais difícil de repetir "do que nas vésperas da Segunda Guerra Mundial” (p. 286).

$\mathrm{Na}$ realidade, "hoje, o capitalismo democrático é uma contradição nos termos" (p. 283), graças à ressurgência política do capital dos anos 1970 em diante, favorecida pela liberalização financeira e comercial, pela globalização realmente existente. É então hoje mais fácil vislumbrar o fim da democracia do que o fim de um capitalismo cada vez mais socialmente desigual, politicamente oligárquico, economicamente medíocre e ambientalmente insustentável. Para um social-democrata, parte da explicação é dolorosa, já que é interna ao movimento, à forma como foi ideologicamente colonizado pelo neoliberalismo e pelo globalismo que lhe é indissociável na prática - de Tony Blair aos Clinton (Bill e Hillary). E isto sem esquecer uma social-democracia europeia esvaziada por uma integração regional por si promovida e que não passa de uma versão extrema da globalização. Um dos capítulos intitula-se precisamente "A desgraça do centro-esquerda”. A derrotada Hillary Clinton (nas eleições à presidência dos EUA em 2016), por exemplo, é o culminar de toda uma abdicação no campo das políticas para a "gente comum", ou seja, das regras que transferem recursos de cima para baixo, ao invés de ser ao contrário. Deixar de falar de classes é meio caminho andado para se passar a considerar "deploráveis" segmentos populares que, pelo contrário, haveria de resgatar da versão reacionária do nacional-populismo. No fundo, como assinala com perspicácia Kuttner, Clinton é o sonho de Steve Bannon tornado realidade: Trump monopolizaria o nacionalismo económico e os democratas, rendidos a Wall Street, ficariam com fragmentos identitários. Para um social-democrata, Kuttner tem ousadia no diagnóstico e na opção estratégica, em particular no resgate do nacionalismo e do populismo das mãos das direitas: sem algum grau de desglobalização, sem a recuperação de alguma soberania para os Estados nacionais no campo da economia política e da política económica - incluindo o recurso ao protecionismo e aos controlos de capitais - não é possível resgatar a democracia e as amplas liberdades para a maioria assalariada. Sem a imaginação nacional e popular a funcionar para democratizar a economia, o campo fica livre para Trump e quejandos. Kuttner faz este exercício tendo mais em atenção os EUA do que outras áreas geográficas, em particular a União Europeia, onde a integração associada ao euro tem duas faces políticas que há que superar desmantelando este projeto monetário: neoliberalismo e neofascismo. A hipótese de uma liderança norte- americana progressista (com Bernie Sanders na presidência dos EUA?), numa espécie de combinação de nacionalismo são e de internacionalismo generoso, subestima as realidades de um mundo felizmente mais multipolar, um dos poucos desenvolvimentos positivos dos últimos anos. Entretanto, se não se regressa já ao capitalismo democrático, talvez seja de ter uma perspetiva mais aberta em relação a Marx e ao socialismo? A resposta é infelizmente negativa, já que Kuttner é demasiado "democrata" para um engajamento sério com a tradição socialista. Neste campo, faria bem em seguir as pisadas de Polanyi: reconhecendo a variedade no marxismo, optaria por um diálogo mais profundo com esta tradição, em particular nos seus momentos estrategicamente mais lúcidos e eticamente mais emancipadores. O casamento entre Marx, 
Keynes e Polanyi é portador de pistas frutíferas para um projeto socialista que não pode deixar de ser um projeto de democratização da economia. Seja como for, o caminho começa por resgatar a democracia da globalização neoliberal, e aî Kuttner é útil para uma social-democracia desorientada dos dois lados do Atlântico.

João Rodrigues

\section{Mazzucato, Mariana (2019), O valor de tudo. Fazer e tirar na economia global. Lisboa: Temas e Debates - Círculo de Leitores, 428 pp. Traduzido por Artur Lopes Cardoso}

Mariana Mazzucato - reputada economista na área da Economia da Inovação e fundadora do Institute for Innovation and Public Purpose da University College London - publicou em 2018 a obra The Value of Everything, traduzida em 2019 para o português. Este livro vem na sequência, como a autora refere desde logo nos agradecimentos de uma obra anterior, The Entrepreneurial State, de 2005, adensando agora um conjunto de argumentos focados no valor.

Estruturado em nove capítulos e escrito numa narrativa dirigida a um público não exclusivamente académico, este livro, ancorado na Economia Política, condensa um conjunto de argumentos centrais para debater questões como: O que é a riqueza? Qual é a origem do valor? Como é ele criado? Quem o cria? Tal como refere Mazzucato no início da obra, "o modo como discutimos o valor afeta o modo como todos nós, desde as gigantescas multinacionais ao lojista mais modesto, nos comportamos como atores na economia e o modo como, por sua vez, se repercute na economia e como medimos o seu desempenho" (p. 22).

Começo por destacar o enquadramento temporal, presente no duplo enfoque histórico que a autora adota na abordagem dos fenómenos e do pensamento económicos e evidenciando como as ideias económicas têm impacto na realidade. É fundamental compreender de que modo, genericamente, a história do pensamento económico é marcada pela evolução do conceito de valor, isto é, desde a identificação do fator que confere valor a um bem ou serviço para o mecanismo que calcula este valor com base no preço desse bem ou serviço no mercado. Esta transformação tem consequências notórias, não apenas na compreensão da realidade, mas também na justificação das ações políticas e económicas que sobre ela incidem.

O livro tem a particularidade de, precisamente, começar e terminar pela abordagem da história do pensamento económico sobre o par por demais debatido: economia versus Estado (capítulos 1, 2 e 8). Nesta discussão, a autora evidencia como as perspetivas sobre o valor foram marcando o olhar sobre os vários atores em presença na estrutura económica e de que forma, no momento presente, o legado hegemónico dos marginalistas conduz a interpretações enviesadas acerca do papel do Estado, concebendo-o como um ator social "improdutivo" e, logo, não criador de valor. Mas basta lembrar, como refere Mazzucato, que "o Estado é amiúde o proprietário de empresas produtivas como caminhos de ferro, serviços postais ou fornecedores de energia" (p. 330).

O livro destaca o facto de os mercados não serem um "dado", mas uma "construção”. A partir de uma aceção da economia como intrinsecamente incrustada na estrutura social (como diria Karl Polanyi), 
Mariana Mazzucato evidencia como os "mercados" resultam de uma multiplicidade e combinações de fatores, cujas configurações exigem uma abordagem da sua complexidade. $\mathrm{Na}$ reflexão sobre a inovação (capítulo 7), encontramos a discussão acerca da criação de produtos e soluções inovadoras. Valerá a pena deter a atenção sobre este capítulo, que considero ser o mais consistente (não sendo de estranhar, atendendo a que é a área de especialização da autora - possivelmente por ser também baseado no livro acima referido, The Entrepreneurial State). Focando casos paradigmáticos como o da indústria farmacêutica e dos setores das tecnologias, a autora chama a atenção para dois aspetos que me parecem essenciais. O primeiro radica no facto de que, como refere, "as narrativas dominantes sobre os inovadores e as razões do seu êxito ignoram, em termos fundamentais, o processo profundamente coletivo e cumulativo que se encontra por detrás da inovação" (pp. 260-261). O segundo aspeto remete para o papel central do Estado no financiamento da investigação científica que sustenta os processos de inovação.

Destaco a extrema relevância do enfoque da autora sobre "a medida", isto é, a forma como os indicadores de desempenho económico (em sentido lato) - como o PIB, os direitos de propriedade intelectual, as patentes, etc. - são, tal como os mercados, socialmente construídos, e, logo, passíveis de questionamento. Subjacente a esta reflexão estão debates e dicotomias vários como, por exemplo, valor versus riqueza ou atividades produtivas versus improdutivas. É fundamental atender às questões de valor e de medida no estudo dos fenómenos económicos, pois, como foi referido, a história do pensamento económico mostra como ambos foram objeto de transformações ao longo da história, e como atividades de extração de valor foram sendo assumidas como atividades de criação de valor. $\mathrm{O}$ universo no qual esta questão surge de forma mais evidente é o dos mercados financeiros (capítulos 4 e 5), onde predominam atividades de extração de valor, já que estes "limitam-se a distribuir rendimento gerado por atividades noutros lugares e não aumentam esse rendimento" (p. 222). A esta evidência soma-se o facto de a lógica de funcionamento da finança se ter alargado a toda a economia "real” (capítulo 6).

O último capítulo, intitulado "Economia da esperança”, surge como um posfácio à obra, no sentido de apontar direções futuras de reflexão e, em particular, caminhos alternativos às leituras dominantes, pugnando por "uma economia que funcione para o bem comum" (p. 361) e, para tal, "recolocando o valor no centro do raciocínio económico” (p. 371). Embora imbuído de algum otimismo, quando refere, por exemplo, que as patentes dos produtos farmacêuticos poderiam ser abolidas (p. 303), esse otimismo pode constituir uma via para pensar e refletir sobre caminhos alternativos que devem ser equacionados no longo prazo, como a autora refere sistematicamente ao longo da sua obra. A obra merece ainda duas notas finais. Uma primeira é a forma por vezes escassa e nem sempre suficientemente esclarecedora - de abordar a complexidade dos fenómenos tidos como "sociais". Um exemplo é a questão da desigualdade, expressa no singular e quase exclusivamente focada nos rendimentos, quando as desigualdades devem ser entendidas no plural, tendo presente a multiplicidade de desigualdades existentes aos níveis social, cultural e político, ultrapassando o domínio económico. Também na abordagem da inovação, penso que é importante equacionar o conjunto de fatores que está na base da sua construção social, bem como incorporar a sua discussão na complexa matriz hierarquizada 
de agendas políticas, atores e interesses. Com esse objetivo seria interessante convocar propostas analíticas de autores como Michel Callon (e a sua abordagem da teoria do ator rede) ${ }^{1}$ ou Pierre Bourdieu (e a sua proposta de problematização do conceito de campo económico). ${ }^{2}$

Uma segunda nota é relativa às opções de linguagem da autora, que articula de forma curiosa um rigor explicativo com expressões mais comuns, visando possivelmente uma aproximação a um público mais amplo. Refiro-me ao uso de expressões como: "os trabalhadores são explorados porque os capitalistas metem ao bolso a mais-valia que os trabalhadores produzem acima das suas necessidades de subsistência" (p. 83); "Ironicamente, o comportamento desastroso dos grandes bancos que desencadeou o crash de 2008 obrigou os reguladores (sobretudo na Europa) a prolongar e complicar ainda mais um processo, que já era árduo, de obtenção de um novo alvará, frustrando o seu plano de soltar uma horda faminta de 'bancos concorrentes'” (p. 165).

Sugiro a leitura deste livro a qualquer cidadão que pretenda ser esclarecido sobre a análise do valor no pensamento económico e as respetivas consequências na estruturação da economia. E que pretenda entender a importância dos nomes que damos às coisas e o impacto que daí advém na configuração da realidade. Logo no início da obra, a autora refere como "As palavras são importantes” (p. 48), quem sabe se parafraseando Nanni Moretti enquanto Michele Apicella, no filme Palombella Rossa (1989), num diálogo irado com uma jornalista. Importa, de facto, refletir sobre as palavras e perceber o poder das narrativas na compreensão do mundo.

Luísa Veloso

\footnotetext{
${ }^{1}$ Ver, por exemplo, Callon, Michel (1986), "The Sociology of an Actor-Network: The Case of the Electric Vehicle”, in Michel Callon; Arie Rip; John Law (orgs.), Mapping the Dynamics of Science and Technology. Sociology of Science in the Real World. London: MacMillan Press, 358-376.

2 Ver, por exemplo, Bourdieu, Pierre (1997), "Le champ économique", Actes de la Recherche en Sciences Sociales, 119, 48-66; Bourdieu, Pierre (2006), As estruturas sociais da economia. Porto: Campo das Letras. Tradução de Lígia Calapez e Pedro Simões; revisão técnica de Carlos Gomes [orig. 2000].
} 


\section{Vicente Ferreira}

Estudante da Licenciatura em Economia no Instituto Superior de Economia e Gestão da Universidade de Lisboa

Rua do Quelhas 6, 1200-781 Lisboa, Portugal

Contacto: vicentecbaf@gmail.com

\section{João Rodrigues}

Faculdade de Economia da Universidade de Coimbra | Centro de Estudos Sociais da Universidade de Coimbra Avenida Dias da Silva, 165, 3004-512 Coimbra, Portugal

Contacto: joaorodrigues@ces.uc.pt

ORCID: https://orcid.org/0000-0001-7595-3162

\section{Luísa Veloso}

ISCTE - Instituto Universitário de Lisboa | Centro de Investigação e Estudos de Sociologia, Instituto Universitário de Lisboa

Av. das Forças Armadas, 1649-026 Lisboa, Portugal

Contacto: luisa.veloso@iscte-iul.pt

ORCID: https://orcid.org/0000-0002-3668-1624 
